\title{
The Use of Videos as a Tool to Reinforce Engineering Economy Course Top- ics: Lessons Learned
}

\section{Mr. Billy Gray, Tarleton State University}

Billy Gray earned his B.S. in manufacturing engineering technology from Tarleton State University, Stephenville, Texas, in 2001 and his M.S. in systems and engineering management from Texas Tech University, Lubbock, Texas, in 2006. He is currently pursuing his $\mathrm{PhD}$ in industrial engineering at the University of Texas at Arlington. He has 10 years of work experience in manufacturing, operations, and engineering management and is currently an assistant professor at Tarleton State University in the Department of Engineering Technology.

\section{Dr. Gloria Margarita Fragoso-Diaz, Tarleton State University}

Dr. Fragoso-Diaz is Assistant Professor of Engineering Technology at Tarleton State University. She received her Ph.D. in Industrial Engineering and Master's degree in Industrial Engineering from New Mexico State University. Dr. Fragoso-Diaz research interest include supply chain optimization, quality and sustainability.

\section{Dr. Erick Jones, University of Texas, Arlington}




\section{The Use of Videos as a Tool to Reinforce Engineering Economy Course Topics: Lessons Learned}

Introduction

At Tarleton State University, Engineering Economy is a required course for the Manufacturing Engineering Technology, Mechanical Engineering Technology, Engineering Physics, and Environmental Engineering degrees while serving as an elective for other technical degrees. The majority of the students are traditional 18-24 year olds. Many of our students are working students who typically carry 20+ hours of work outside of their school work. The majority of our students are from within the surrounding 300 miles of the main campus in Stephenville, Texas.

The course utilizes Newnan, Eschenbach, and Lavelle's Engineering Economic Analysis as the textbook. Traditionally the course has been set up to teach the basic mechanics in the first section of the course, the decision making process in the second section of the course, and taxes, depreciation, and other accounting practices in the third section of the course. The area that our students typically stumble in is the decision making process. Analysis from their tests showed that they were making mistakes in the mechanics of the problems, i.e. not identifying the correct variables, utilizing the incorrect formulas, or not being able to break down the written problem correctly. This had led us to evaluate how we teach the class and to see if we can change how the material is delivered to the students.

As with many solutions today, the use of technology to enable the class was selected to push the information to the students. It consisted of instructor-produced videos relating to the topics being covered in classroom. This was expected to allow the instructor the ability to provide more guided examples for the students to work thus providing more support in the areas that the students were seen as deficient in. The videos cover all of the homework problems in an effort to reach the student outside of the classroom. The online support system in the university is BlackBoard and videos can be posted there for students to use at any time. The class has also been expanded to include instruction on working engineering economic problems in Excel during the second section. Additionally, students are required to discuss current economic topics and explain how those topics tie into the course. For this activity, students are encouraged to utilize Twitter and other social media outlets to find events to bring back to class. A recent study provided evidence of twitter as an effective tool for classroom engagement. ${ }^{5}$

For this paper, the focus is on the use of videos that explain the homework problems as a support for the coursework. The test scores for the first and second tests will be evaluated to determine significance in the grades comparing several populations. The null hypothesis is that the use of videos supporting homework does not change test scores for the first and second tests. Our alternative hypothesis is that the use of videos that cover the homework problems would reflect a change in test scores for the first and second sections of the classes. The evaluation is done at a $95 \%$ confidence level $(\alpha=0.05)$. 
The rest of this paper is broken down into Background on the use of videos to support the class, Methods used to develop the additional coursework, Results of the courses evaluated and how the use of videos affected the test grades, and Conclusion, which ties up the paper and discusses next steps.

Background

Most of the students we are currently teaching are from the Millennial generation. These students grew up with the internet and digital technology. ${ }^{2,4}$ They are the first generation to be completely immersed in information their entire lives and the first "generation to have access to more information than any other generation in history.",2

There have been several methods used in reaching these students and teaching topics to them beyond the classroom. The Khan Academy is one such method. It has developed into video sessions available in Khan's website or posted on YouTube.com where the parts of the material that cause the most confusion can be reviewed over and over until the student understands the concept. ${ }^{7}$ A second method is online tutoring. Many of these types of sessions let students log into the tutor's system and receive help on any type of subject the tutor can provide. ${ }^{6}$ This method, however, relies on the tutor teaching the material in a manner consistent with how the material is shown in class. A third method is the homework help from sources such as Chegg.com. ${ }^{6}$ Chegg is an academic company where students can log onto the site and post problems they have for class so that other users can post help and answers to those questions.

One of the instructional tools discussed in the literature for web-based materials is the use of video recordings. It is discussed how software allows an instructor the tool of video as an efficient manner to provide the basics of engineering economy. ${ }^{1}$ This allows the instructor to push the videos online so that their students can have remedial instruction or it allows the instructor to push the entire class onto the online environment. This is a similar concept to the Open Courseware solution where some universities have posted online videos and materials of courses from past semesters for the public to use and to educate themselves.

The video method also helps lead to the flipped classroom concept where the students are expected to watch the lecture over the materials prior to showing up to class for discussion of the materials. ${ }^{3}$ Though students should be reading the materials prior to class, the videos and recorded instruction tend to appeal more to this generation, who tend to be more accustomed to learning through digital content. One of the pitfalls with the flipped classroom concept noted, is that the videos must be carefully tailored to prepare the students for the class activities. ${ }^{3}$ Additionally, teacher-created videos are often marginal in quality and are time consuming to create. ${ }^{3}$ This may lead to videos creating more of a barrier to learning than a help in disseminating information to the students. 


\section{Method}

Before we added technology or changed how we delivered the material, we evaluated the previous tests to determine what areas of the materials were not being retained by the students. Test 1 showed that the students who did poorly did not understand which components of the problem were used as which variable. Test 2 showed that the same students who did poorly on Test 1 still did not understand the mechanics of the problems. Test 2 also showed that students did not completely understand which tools to employ during different decision analysis portions of the test problems, i.e. when to use NPW or EUAC over incremental analysis.

Based on conversations with the students they felt that they would benefit with extra problems worked with the instructor. Because of time constraints we decided to work the problems out on video and push those to Blackboard so that students could watch the videos on their own time. The problems that were chosen were the homework problems since they were selected based on how they would support the problems the students worked on the tests. The instructor focused the recordings on how to set up the problems, the structure of how every problem should be worked out, why the instructor chose certain variables, why the formulas were selected and how the instructor knew the correct formulas to choose. It was felt that by working the problems out this way that the instructor would have one more opportunity to communicate with the students about the class materials.

When evaluating the technology used to develop the videos, a flexible interface that would allow the instructor to record at their convenience was sought. The use of an iPad and the app ShowMe was eventually selected. This allowed the instructor to record even when they were at home or had down time on the road. The ShowMe (ShowMe.com) app is a screen capture application that also captures voice so that as the instructors are recording they can narrate the problem. Graphics can be imported into the app and discussed. The ShowMe app could even be used to record a help session and the video link emailed to the student afterwards to help reinforce the session.

To determine if the video had an impact we evaluated two engineering economy courses that did not utilize the videos for class and two courses that did utilize videos for class. Both classes without video and both classes with video are evaluated to verify that there is not a significant difference between the classes and then evaluated to determine if there is significance between the classes without video and the classes with video support.

The significance between the two classes will be determined using the average grades and standard deviation in the grades to see if the test grades have changed with the introduction of the videos.

Results

The first step was to evaluate the classes without videos (S12 and F12) against each other to determine if there was a significant difference between the two classes. Then the two classes 
taught with the videos (S13 and F13) were evaluated to determine if those classes were significantly different. Table 1 shows the test averages and their corresponding standard deviations.

Table 1 Summary of Test Averages and Standard Deviations (s)

\begin{tabular}{llcccc} 
& Course & $\begin{array}{c}\text { Test 1 } \\
\text { Average }\end{array}$ & $\begin{array}{c}\text { Test 1 } \\
\text { s }\end{array}$ & $\begin{array}{c}\text { Test 2 } \\
\text { Average }\end{array}$ & $\begin{array}{c}\text { Test 2 } \\
\text { s }\end{array}$ \\
\hline Without videos & S 12 & 85.8 & 10.1 & 76.8 & 15.0 \\
& F 12 & 90.5 & 7.9 & 77.6 & 16.4 \\
\hline With Videos & S 13 & 87.8 & 9.0 & 68.2 & 14.5 \\
& F 13 & 80.2 & 17.0 & 73.4 & 17.1 \\
\hline
\end{tabular}

Minitab was utilized to perform the analysis. It was determined, that the average test scores for Test 1 and Test 2 for both without video populations and both with video populations were not significantly different at the $\alpha=0.05$ level.

The second step consisted in evaluating the without video population (Y12) versus the with video (Y13) population. The averages and standard deviations for Test 1 and Test 2 are shown in Table 2.

Table 2 Summary of Averages and Standard Deviations (s) by Population Of Courses Without Video and With Video Support

\begin{tabular}{lccccc} 
& Course & $\begin{array}{c}\text { Test 1 } \\
\text { Average }\end{array}$ & $\begin{array}{c}\text { Test } \\
\text { 1 s }\end{array}$ & $\begin{array}{c}\text { Test 2 } \\
\text { Average }\end{array}$ & $\begin{array}{c}\text { Test 2 } \\
\text { s }\end{array}$ \\
\hline Without Video & Y 12 & 88.7 & 9.0 & 77.3 & 15.7 \\
\hline With Video & Y 13 & 82.8 & 15.2 & 71.6 & 16.3 \\
\hline
\end{tabular}

In the second step, it was determined that the Test 1 averages between populations were significantly different with a p-value of 0.024 while Test 2 averages for both populations were not significantly different. This results in rejecting $\mathrm{H}_{0}$ for Test 1 and accepting that there was a change in the test scores by students on Test 1 . Further analysis of the data shows that there was a significant decrease in the Test 1 averages after the inclusion of the videos. Evaluation of Test 2 leads us to fail to reject $\mathrm{H}_{0}$ meaning that there is no significant change in the test scores on Test 2 by including video support.

Unfortunately, the data shows a regression in the test scores. Possible causes for the reduction in grades are the quality of the information used in the videos, the videos were not used by the students, the videos were partially used by the students to complete homework assignments, and that the videos did not hold the students' attention. The quality of information refers to the type 
of information that the student needed. If the student did not understand where a variable came from or why compounded interest was used instead of simple interest, then the video needs to address those shortcomings. This may lead back into the planning of the videos and how much time the instructor actually needs in order to plan and produce the video.

The particular application used for this exercise, ShowMe, automatically tracks the number of views for each video. BlackBoard application also has a feature that will track the number of views for a video. Evaluation of the video counts reveals that the number of views exceeded the number in the population which hints at the use of the videos by students more than once. Since it is unclear whether either application logs who views the videos there is uncertainty as to whom watches.

There is also the case of how much of the video the students watch. Due to the time restraints on the instructor, homework is graded as completion. Solutions are spot checked but the student is encouraged to work problems. The possibility exists that the some students only utilized specific segments of the videos in order to write down the correct solutions. In this case they would skew the numbers down, showing that they viewed the videos but they would have built a false impression that they knew the materials because of their homework grades though they would have a lesser idea of how to actually do the work.

As stated by Herreid and Schiller (2013), the quality of the teacher-created videos is often marginal. ${ }^{3}$ This includes how the instructor sounds on video, the clarity of the writing or text, to the size and ability to download the video from the internet. If the instructor speaks with an accent or is too loud or too soft then it is probably difficult to pay attention to the videos. The same could be said of an instructor who is tired or hurried or in a noisy location. The use of the iPad and a stylus yields decent videos but some videos may be too busy or display the information in a manner that makes it difficult to interpret. Lastly, long videos at high quality make large files. If a student is in a remote location or has less than optimal equipment, the videos may not transfer well.

\section{Conclusion}

Though the results of the study are counter to original intention of the video exercise, it does yield useful information about steps forward not only for engineering economy but also for other courses. First is that the instructor will need to continue building upon what has been started. The videos may need to be adjusted to where they are only available after a problem has been submitted in Blackboard. Then the student can see the video about why they did not provide the correct answer. Second, the material in the videos should be reviewed by another instructor to help determine if it is thorough enough. This should be done during the planning phase as a check before the time and effort is expended creating the complete video. Lastly, the time has to be set aside where the instructor will not be interrupted so that they can focus on the production 
of the videos. The instructor could even oversee the video while someone who is a better narrator give direction on the video.

Further steps for this class will be to evaluate the homework assignments and their impact on the tests. This would help ensure that the problems worked for the homework actually correlated to problems that were on the tests. Additionally, future research will include analyzing the inclusion of readily available technology such as Twitter to enhance the learning experience in Engineering Economy courses since it is already used in the course.

\section{References}

1. Blank, Leland, Phillip Borrowman, Hector Carrasco, Heather Nachtmann, and John White. "Inclusion of Engineering Economy Concepts and Techniques in B.S. Engineering Curricula." The Engineering Economist 56 (2011): 193 - 204.

2. Considine, David, Julie Horton, and Gary Moorman. "Teaching and Reading the Millinial Generation Through Media Literacy." Journal of Adolescent \& Adult Literacy 52, no. 6 (2009): 471 - 481.

3. Herreid, Clyde Freeman, and Nancy A. Schiller. "Case Studies and the Flipped Classroom." Journal of College Science Teaching 42, no. 5 (2013).

4. Howe, Neil, and William Strauss. Millenials rising: The next great generation. New York: Vintage Books, 2000.

5. Junco, R., Heiberger, G. and Loken, E. "The effect of Twitter on college student engagement and grades." Journal of Computer Assisted Learning , 2010: 119/132.

6. Shellenbarger, Sue. "The Invasion of the Online Tutors." Wall Street Journal. November 12, 2013.

7. Thompson, Clive. "How Khan Academy is Changing the Rules of Education." Wired.com. July 15, 2011. 